\title{
Is artificial habitat diversity a key to restoring nurseries for juvenile coastal fish? Ex situ experiments on habitat selection and survival of juvenile seabreams
}

\author{
Mercader Manon 1, 2, ${ }^{*}$, Blazy Christophe 1,2, Di Pane Julien ${ }^{3}$, Devissi Camille 1,2, \\ Mercière Alexandre ${ }^{1,2}$, Cheminée Adrien ${ }^{1,2,4}$, Thiriet Pierre ${ }^{5,6}$, Pastor Jérémy ${ }^{1,2}$, \\ Crec'Hriou Romain ${ }^{1,2}$, Verdoit--jarraya Marion ${ }^{1,2}$, Lenfant Philippe ${ }^{1,2}$
}

${ }^{1}$ Centre de Formation et de Recherche sur les Environnements MéditerranéensUniversité Perpignan Via Domitia UMR 5110, F-66860 Perpignan ,France

${ }^{2}$ Centre de Formation et de Recherche sur les Environnements MéditerranéensCNRS UMR 5110, F66860 Perpignan, France

3 Ifremer-Institut Français de Recherche pour l'Exploitation de la Mer 62200 Boulogne-sur-Mer, France

4 Septentrion EnvironnementPort des Goudes 13008 Marseille, France

5 UMS PATRINAT (AFB, CNRS, MNHN)Muséum National d'Histoire Naturelle CP 41-Maison Buffon, 36 rue Geoffroy Saint-Hilaire 75231 Paris Cedex 05 France

${ }^{6}$ Station Marine de DinardMuséum National d'Histoire Naturelle 38 rue de Port Blanc 35800

Dinard ,France

*Corresponding author : Manon Mercader, email address : manon.mercader@univ-perp.fr

\begin{abstract}
:
Man-made infrastructures have become ubiquitous components of coastal landscapes, leading to habitat modification that affects the abundance and diversity of marine organisms. Marine coastal fish have a complex life cycle requiring different essential habitats. One of these habitats is known as a nursery, a place where juveniles can settle in large numbers, survive, and grow to contribute to the adult population. Nurseries are mainly found in shallow, sheltered zones and are thus particularly impacted by urbanization, notably by harbors. The vertical featureless structure of docks is very unlikely to be used by juveniles, which need complex habitats to find food and shelter from predators. Recent attempts to rehabilitate the nursery function in such environments by using artificial habitats have proven efficient in increasing juvenile densities. However, nothing is known about the survival of juveniles in these habitats, preventing any conclusions on the effectiveness of this means of restoration from being drawn. Here, we set up tank experiments to test the relationship between habitat preferences and the survival rate of two species of seabream when facing stalkattacking combers. Habitat choice was consistent with survival results, indicating that artificial habitats might not represent unintended ecological traps for juveniles. However, the artificial habitats' effect on survival was variable between species. Therefore, our results suggest that habitat diversity might be of prime importance to sustain juveniles of different species and stress the need for the development of diverse artificial habitats to counteract the effects of seascape homogenization.
\end{abstract}

Keywords: artificial habitat, habitat selection, marine restoration, nursery, seascape homogenization, survival rate 
63 - The effectiveness of artificial habitats as nurseries is species dependent. An

64 artificial habitat can have a beneficial effect by being selected by juveniles and

65 enabling a good survival rate or represent a potential "equal-preference trap" by

66 leading to a lower survival rate and not being avoided. Additionally, the

67 rehabilitation of nursery function should favor diverse artificial habitats to

68 benefit multiple species and developmental stages.

69 - Management efforts to maintain coastal fish populations should include the

70 conservation of remaining natural nursery habitats and the rehabilitation of

$71 \quad$ degraded environments.

72 - To gain efficiency, marine coastal restoration requires the implementation of a

73 diversity of solutions, which need to be developed and tested in a collaborative

$74 \quad$ way among engineers, managers and scientists. 


\section{Introduction}

Landscape modification resulting from habitat degradation, fragmentation or loss is known to be a key driver of species extinction leading to biodiversity loss in all ecosystems (Foley 2005; Hewitt et al. 2010). Homogenized landscapes impact not only the abundance of organisms but also the structure of communities and the functioning of ecosystems (Brokovich et al. 2006; Fischer \& Lindenmayer 2007), reducing valuable functions and services (Cardinale et al. 2012). For marine ecosystems, this threat is particularly intense in coastal areas, where the human population and its ensuing pressures are concentrated (Airoldi \& Beck 2007) while being crucial for the early life stages of many species. Indeed, the heterogeneity of the coastal seascape results in a large variety of habitats providing food and shelter essential for juveniles (Beck et al. 2001). Habitat homogenization and simplification might then threaten the nursery function played by coastal areas (Cheminée et al. 2016; Piko \& Szedlmayer 2007). The nursery value of a habitat is given by its relative contribution to the adult population by comparison to other nearby habitats. This contribution is the result of four factors: (i) initial density (better settlement), (ii) survival rate, (iii) growth rate and (iv) migration toward adult habitats (recruitment) (Beck et al. 2001). Mortality during early fish life is high, reaching more than $90 \%$ by the end of the larval stage (Houde \& Hoyt 1987), and post-settlement processes, such as juvenile growth and survival, which are directly linked to habitat availability and quality, are known to be of prime importance in the sustainability of populations (Nagelkerken et al. 2015). In recognition of the risk that coastal development might pose to marine populations, increasing efforts are being made to restore coastal habitats (Brown \& Chapman 2014; Paalvast et al. 2012; Sella \& Perkol-Finkel 2015). On the shoreline, harbors are the most common coastal 
100 infrastructures, and they have serious detrimental environmental impacts (Meinesz et

101 al. 1991; Martin et al. 2005; Neira et al. 2011; Falandysz et al. 2002). With regard to 102 coastal fish population maintenance, they may represent a risk, notably by acting as 103 traps in which larvae can arrive but will not find suitable habitat to settle and survive. 104 Indeed, the featureless nature of docks is very unlikely to provide them the food and 105 shelter they need (Mercader et al. 2018). To mitigate this effect, programs of 106 rehabilitation of the nursery function for coastal fish have been initiated within harbors.

107 The first results showed that increasing habitat complexity by using small artificial 108 habitats leads to increased juvenile densities (Bouchoucha et al. 2016; Mercader et al. 109 2017; Patranella et al. 2017). However, the observation of higher juvenile densities is 110 not enough to draw a conclusion about the nursery role of artificial habitats or the 111 success of rehabilitation. Indeed, the observation of higher densities could be the result 112 of a simple concentration effect (Brickhill et al. 2005), which might induce adverse 113 effects if the fitness of the juveniles on artificial habitats is lower than that on other 114 available habitats. Preferential settling on artificial habitats could, for example, make 115 juveniles more accessible to predators or induce greater competition for nutritional 116 resources, inducing higher mortality. In such cases, the use of artificial habitats for 117 harbor rehabilitation could lead to the formation of ecological traps (habitats preferred 118 by animals but in which their fitness is lower than that in other available habitats) 119 (Robertson \& Hutto 2006). Rehabilitation would not only be unsuccessful but could also 120 compromise population persistence and increase extinction risk (Hale et al. 2015a; 121 Battin 2004). Traps are known unintended consequences of management and 122 restoration activities (Robertson et al. 2013; Hale et al. 2015b). Additionally, assessing 123 the survival rate and habitat preference is a key element to guide restoration efforts 124 because successful restoration results from the provision of suitable habitats (providing 
125 required resources to targeted species), which animals must perceive as appropriate

126 and colonize (Hale \& Swearer 2017; Van Dyck 2012; Andrews et al. 2015). In that

127 context, the main objective of this work was to determine whether artificial habitats

128 used for harbor rehabilitation could represent ecological traps for juvenile fish. To do so,

129 we tested the following hypotheses: (i) mortality of juvenile fish is not higher on

130 artificial habitats than on other habitats, and (ii) juveniles are selecting the habitat that

131 provides lower mortality (i.e., the better survival rate).

132 For juvenile coastal fish predation, competition for shelter and starvation are the main 133 causes for density-dependent mortality (Hixon \& Jones 2005). While other causes of 134 mortality exist (pollution, diseases...), we focused our study on predation-induced 135 mortality. Juvenile depletion from a given habitat results from two distinct processes, 136 mortality and emigration, which are difficult to differentiate in open environments. 137 Previous studies revealed that in the Mediterranean Sea, artificial habitats used for 138 harbor restoration are mainly used by Diplodus spp. (seabream) (Bouchoucha et al. 139 2016). At the juvenile stage, these species do not undergo large displacement, but they 140 can still move at the scale of a whole cove (Macpherson 1998), which prevents accurate 141 study of their mortality on the smaller scale represented by artificial habitats. 142 Furthermore, visibility inside harbors is often poor, making it difficult to precisely follow 143 cohorts. Given these ecological constraints, tank experiments represent a good 144 alternative for studying the mortality of juvenile seabreams. A first set of experiments 145 permitted (i) the estimation of predation-induced mortality rates of juveniles on 146 different habitat types and (ii) the exploration of the influence of those habitats on prey 147 and predator behavior. A second set of experiments was designed (iii) to determine the 148 habitat preferences of juveniles. Based on the criteria outlined by Robertson $\_$\& 149 (2006), the combination of the results allowed us to test our hypothesis and to assess 
150 the relationship between habitat selection and survival to identify if these habitats could

151 represent potential ecological traps.

152

153 Methods

154 Studied fishes

155 We focused on the juveniles of two sparid species: the two-banded seabream (Diplodus 156 vulgaris (Geoffroy Saint-Hilaire, 1817)) and the white seabream (Diplodus sargus 157 (Linnaeus, 1758)), which were used as model prey species. These species are common 158 in Mediterranean coastal waters, and their high commercial value places them among 159 the most harvested species by local artisanal fisheries (Coll et al. 2004; Lloret et al. 160 2008). The juveniles settle in shallow heterogeneous rocky habitats made of small 161 blocks, pebbles or coarse sand, and their life cycle and behavior at settlement are 162 representative of those of most coastal nektobenthic fish species (Planes et al. 1998; 163 Macpherson 1998; Harmelin-Vivien et al. 1995). Both species can also be found in high 164 densities on artificial structures such as breakwaters or jetties (Clynick 2008; Pastor et 165 al. 2013) and have been observed inside harbors (Bouchoucha et al. 2016; Mercader et 166 al. 2018, 2017). If they use the same habitats as nurseries, they do not settle during the 167 same time period: D. vulgaris post-larvae reach the shore from December to March, 168 while $D$. sargus post-larvae arrive between May and June, which avoids competition 169 between these two species. D. vulgaris is also more opportunistic and can settle slightly 170 deeper in the ecotone between rocky bottom and shallow meadows (Vigliola \& 171 Harmelin-Vivien 2001).

172 We used the comber (Serranus cabrilla (Linnaeus, 1758)) as a predator model. This 173 abundant species mainly lives around rocky substrates and meadows, which constitute 174 suitable habitats for its stalk-attacking strategy to predate. The comber is an 
175 opportunistic macrocarnivore and one of the most important predators of small fish

176 (Cresson et al. 2014; Stergiou \& Karpouzi 2002). Its small size (10 to $25 \mathrm{~cm}$ as an adult)

177 and its aggressive nature also make it a good model for predation tank experiments.

179 Fish collection and housing

180 Individuals were collected in the natural environment. None of these species are 181 endangered or protected, and sampling did not include any sites within marine 182 protected areas. Fishing protocols and sites were approved by the Direction Inter183 Régionale de la Mer (DIRM, the French administration of maritime affairs) under permit $184 \mathrm{n}^{\mathrm{0}}$ 560. Fishes were captured on two expeditions, corresponding to the prey model's 185 arrival on the coast, in February (for D. vulgaris) and June (for D. sargus) 2016. For both 186 expeditions, captures were performed at the same sites of the French Catalan coast using hand nets for seabreams and lines and hooks for combers. After collection, juveniles were held in $500 \mathrm{~L}$ tanks with a maximum of 200

189 individuals/tank to minimize damage and stress. Combers were placed individually in 190 tanks of $45 \mathrm{~L}$ to avoid any aggressive behavior among them. All tanks (housing and 191 experimental, see next section) were connected to the same filtration system filled with 192 natural seawater. The water temperature was different between the expeditions to 193 mirror natural conditions: $17^{\circ} \mathrm{C}$ in February and $22{ }^{\circ} \mathrm{C}$ in June. The salinity (37), pH (8), 194 and photoperiod (12 h/day of artificial light) were constant throughout all experimental 195 expeditions. Physicochemical parameters $\left(\mathrm{pH}, \mathrm{NH}_{3}, \mathrm{NO}_{2}, \mathrm{NO}_{3}\right.$, salinity and temperature) 196 were checked and adjusted twice a week. Fish were acclimated for two weeks before 197 starting the experiments to allow them to recover from catching. Juveniles were fed 198 twice a day with defrosted Artemia sp.; combers, once a day with defrosted Atherina sp. 199 Combers were not fed for $48 \mathrm{~h}$ before each experiment to ensure that they were all in 
200 the same starvation state at the beginning of all trials. At the time of experiments, the

201 fish were at a mean size of $2.4 \pm 0.1 \mathrm{~cm}$ for $D$. vulgaris and $2.3 \pm 0.2 \mathrm{~cm}$ for D. sargus. The

202 sizes of $S$. cabrilla were $15.1 \pm 1.8 \mathrm{~cm}$ and $15.5 \pm 1.4 \mathrm{~cm}$ for experiments with $D$. vulgaris 203 and D. sargus, respectively. Once the experiments were performed, all predators and 204 juveniles that had not been eaten were released alive at their capture site.

206 Experimental design

207 All experiments were held in $100 \times 50 \times 40 \mathrm{~cm}$ tanks connected to the same filtration 208 system as the holding tanks. For mortality experiments, an activated carbon filter was 209 added to each experimental tank between each trial to clear away dissolved fish 210 chemicals from trial to trial (Martin et al. 2010). To avoid any disturbance, filtration and 211 air pumps were turned off during the whole duration of the experiments.

212 The bottom of all tanks was covered with a green velour carpet; the back and the sides 213 of the tanks were masked with auto-adhesive blue film to prevent exterior perturbations 214 during experimental trials. We conceived of four different types of habitats, two of which 215 mimicked typical natural nursery habitats for sparids: rocky chaotic clusters (R) and 216 Posidonia oceanica meadow (M), one artificial habitat similar to those used in recent 217 ecological restoration projects $(\mathrm{AH})$ and a control (C) (Figure 1). Each habitat was 218 conceived to occupy a $60 \mathrm{dm}^{3}$ volume, dividable into two equivalent parts (of $30 \mathrm{dm}^{3}$ ), 219 so it could be used in both experiments (mortality and habitat selection). Rocky chaotic 220 clusters consisted of quarry stones randomly placed in the aquarium to provide 221 heterogeneous shapes and sizes of cavities. The stones were piled up to form a $22225 \times 25 \times 100 \mathrm{~cm}$ habitat. Meadows were made of plastic algae fixed to two $50 \times 25 \mathrm{~cm}$ 223 Plexiglas planks (for a total dimension of $25 \times 25 \times 100 \mathrm{~cm}$ ). Each plank was composed of 22412 feet with 20 leaves of $20 \mathrm{~cm}$ height and 10 feet with 12 leaves of $25 \mathrm{~cm}$ dispersed 
225 randomly. The total leaf density resulting from the dispersal was 2880 leaves $/ \mathrm{m}^{2}$ for

$22695 \%$ to $100 \%$ recovery, corresponding to a medium-density meadow (Buia et al. 2004),

227 which is representative of what can be found in the area between 0 and $3 \mathrm{~m}$ depth

228 (Rotini et al. 2013). The artificial habitat used was composed of a pair of stainless steel

229 alloy cages of different mesh sizes ( $5 \mathrm{~cm}$ for the outer cage, $2.5 \mathrm{~cm}$ for the inner), the

230 inner cage being filled with oyster shells (see Bouchoucha et al. (2016) for full

231 description). The original version of this habitat was an $80 \times 25 \times 50 \mathrm{~cm}$ rectangle. Here,

232 we used two smaller versions of $30 \times 25 \times 35 \mathrm{~cm}$, which were hung from the top of the

233 tank, leaving a $5 \mathrm{~cm}$ space between the tank bottom and the habitat. For the control, two

234 weighted plastic tubes ( $\mathrm{L}=20 \mathrm{~cm}, \emptyset=8 \mathrm{~cm}$ ) were placed in the tanks to avoid comber

235 stress due to the total absence of habitat.

237 Survival

238 Four tanks were used, each presenting a habitat (AH, M, R or C) occupying a volume of $23960 \mathrm{dm}^{3}$ (Fig. 1a - d). A see-through plastic plank was placed in the middle of the tank to 240 divide it into two halves, preventing encounters between prey and predator but letting 241 them see each other. Five juveniles were placed on one side and a predator on the other 242 for $30 \mathrm{~min}$, allowing them time to recover from manipulation, acclimate to the new tank 243 and explore the habitat. The position (right or left) of the juveniles and the predator 244 during this acclimation was switched for each replicate. After $30 \mathrm{~min}$, the plastic plank 245 was removed and experimentation began. For $2 \mathrm{~h}$, tanks were recorded using a camera 246 (GoPro HER03) placed in front of the tank, allowing the measurement of the exact time 247 of every predation event. In addition, behavioral data (numbers of approaches, attacks 248 and escapes, $c f$. Table S1 for the description of each behavior) were recorded every $30 \mathrm{~s}$ 249 by direct observation during the first $30 \mathrm{~min}$ of experimentation. At the end of the 
experiment, surviving juveniles and predators were removed from experimental tanks.

251 Predators were replaced in their individual tanks, and juveniles were put in a new

252 housing tank to avoid using them a second time. For each habitat type and each prey 253 species, eight trials were run. To ensure complete randomization, each habitat was 254 placed in a tank for two runs and then moved to the next tank until it had been placed 255 twice in each tank. To prevent predators from encountering the same habitat twice (and 256 thus risking the predators learning the environment) and to limit potential bias due to 257 interindividual behavioral variability, two combers were randomly assigned to a tank in 258 such a way that each of them would run the experiment once for each habitat.

260 Habitat selection

261 Habitat selection was investigated for juveniles of the two species, D. vulgaris and $D$. 262 sargus. Experiments were held in a unique tank. Habitats were arranged in the tank in 263 combinations of two (M/AH, R/AH, M/R), with each habitat occupying half of the tank 264 and representing a volume of $30 \mathrm{dm}^{3}$ (Fig. 1e - g). In addition to the three combinations, 265 three control experiments were carried out in which the same habitat was present in the 266 whole tank (AH1/AH2, M1/M2, R1/R2) (Fig. 1h - j). Five juveniles were placed in the 267 middle of the tank, and observations began 1 min after their introduction. The same 268 camera as the one used for survival experiments was placed in front of the tank and was 269 set to take a picture every $2 \mathrm{~s}$ for $5 \mathrm{~min}$ to determine the position of the juveniles ( $c f$. 270 next section). As with the previous experiments, all fishes were removed from the tank 271 and placed in a separate housing tank to avoid using the same fish twice. Eight replicates 272 were run for each habitat type for both species. 
275 Videos of survival experiments were used to report the time at which each lethal 276 interaction occurred and to allow the calculation of the mortality kinetics. As mentioned

277 previously, qualitative behavioral data were recorded only for the first $30 \mathrm{~min}$.

278 For habitat selection, pictures were first corrected for the distortion due to the fish eye 279 of the camera using Photoshop (version CC 2015). The position of the fish in an X-Y 280 plane was then incremented using ImageJ (version 1.51j8). Due to battery issues, only 4 $281 \mathrm{~min} 30 \mathrm{~s}$ (out of the intended $5 \mathrm{~min}$ ) could be analyzed for all trials, which still 282 represents 130 pictures, 650 coordinates per replicate and 5200 coordinates per 283 treatment $(\mathrm{M} / \mathrm{AH}, \mathrm{R} / \mathrm{AH}, \mathrm{M} / \mathrm{R}, \mathrm{AH} 1 / \mathrm{AH} 2, \mathrm{M} 1 / \mathrm{M} 2, \mathrm{R} 1 / \mathrm{R} 2)$. The intermediate area 284 separating the two habitats in a tank was used as a limit to evenly divide each tank into 285 two parts corresponding to the different habitats. Each pair of coordinates was then 286 assigned to a habitat.

Statistical analysis

289 For all statistical analyses, the significance threshold was fixed at 0.05 . The survival and 290 habitat selection analysis, which respectively test the survival function and Jacob's 291 Selection index as response variables, were run in R (R Core Team 2017). Behavioral 292 analysis of the multivariate response data (number of each behavior) was performed 293 using PRIMER 6 software with the PERMANOVA add-on (Clarke et al. 2014).

\section{Effect of habitat on juvenile survival}

296 To compare the survival of the juveniles between the four habitats (AH, R, M and C), we 297 determined juvenile survival probabilities in each habitat using the Kaplan-Meier (KM) method. This method allows to nonparametrically estimate the survival probability for censored and uncensored survival times (Kaplan \& Meier 1958). Equality of the survival 
300 function between habitats was tested using the Peto and Peto modification of the Gehan-

301 Wilcoxon test because the hazard ratio was not constant over time and was not

302 proportional between habitats (Diez 2013). If the hypothesis of equality was rejected,

303 pairwise comparisons were performed using the Peto and Peto test with BH-adjusted p-

304 values (Benjamini \& Hochberg 1995). All survival analyses were performed using the

305 "survival" package (Therneau 2015) for the R environment.

306

307 Fish Behavior

308 To compare the behavioral patterns of the fishes between habitats, we used the total

309 number of observed behaviors for each behavioral variable (Approach, Attack and

310 Escape) in each trial as response variables. Multivariate analyses of variance were

311 performed on Bray-Curtis dissimilarity matrices with the addition of a dummy variable.

312 P-values were calculated by 999 random permutations of unrestricted raw data, as our

313 design contained only one factor (habitat), and Type III sum of squares (Anderson

314 2001a). The Monte Carlo test was used when fewer than 200 permutations were

315 generated. Post hoc pairwise tests were performed when relevant. SIMPER analyses

316 were conducted when PERMANOVAs were significant to determine the relative

317 contribution of each behavioral variable to differences between habitats.

319 Habitat selection

320 Jacob's Selection Index (SI) (Jacobs 1974) was used to determine which habitat (AH, M

321 or R) juvenile fishes preferentially chose. For each of the height replicates, SI was

322 calculated with 650 points (X-Y coordinates) corresponding to the position of each of

323 the five juveniles every two seconds. This index is based on the following formula: 
324 SI $=(\mathbf{n H 1}-\mathbf{n H 2}) /(\mathbf{n H 1}+\mathbf{n H 2})$, where $\mathrm{n}$ refers to the number of points observed in 325 habitat 1 (H1) and in habitat 2 (H2). This index ranges between -1 and 1 . SI $=-1$ 326 indicates a preferential choice for habitat $1, \mathrm{SI}=1$ for habitat $2, \mathrm{SI}=0$ indicates no 327 particular choice. SI values were then used as response variables and compared to zero

328 (for controls and combinations) using a one-sample Wilcoxon test. If controls differ from 329 zero, observed choices are not linked to habitat type but to other unknown factors. If 330 controls do not differ from zero but a combination does differ from zero, juvenile fish 331 made a significant choice toward a habitat.

\section{Results}

334 Survival

335 Habitat type significantly influenced juvenile survival probabilities for both species 336 (Peto \& Peto test, p-value 0.002 for D. vulgaris and p-value $=0.0053$ for D. sargus), but 337 this effect was very different depending on the species. For D. vulgaris, the mean survival 338 time was the lowest on the meadow habitat $(88.88 \pm 6.06 \mathrm{~min})$, significantly lower 339 (pairwise Peto \& Peto p-value $=0.009$ ) than that on the $\mathrm{AH}$, which provided the best 340 survival time $(108.16 \pm 5.18 \mathrm{~min})$. Survival on the control and rock was intermediate 341 (98.43 $\pm 6.70 \mathrm{~min}$ and $93.38 \pm 6.92 \mathrm{~min}$, respectively) (Fig. 2a; Table S2a). For D. sargus, 342 survival was equivalent on the control $(115.40 \pm 2.60 \mathrm{~min})$, meadow $(115.23 \pm 2.84$ $343 \mathrm{~min})$ and rock $(115.22 \pm 2.41 \mathrm{~min})$ but lower on the AH $(98.23 \pm 6.24 \mathrm{~min}$, pairwise Peto

$344 \&$ Peto p-value $=0.038$ for all three combinations) (Fig. 2b; Table S2b). Mortality was 345 globally lower for D. sargus than for D. vulgaris (14 and 29\%, respectively, of total 346 juveniles were eaten). It is also interesting to note that the lowest survival probability 347 (at the end of the 120 min experiment) for D. sargus (on the $\mathrm{AH}$ ) was equivalent to the 348 survival probability for D. vulgaris on rock (upper 0.86 , mean 0.70 , lower 0.57 ). 
$350 \quad$ Fish behavior

351 Behavioral patterns varied slightly according to habitat type. For D. vulgaris, these 352 differences were significant (PERMANOVA p-value $=0.004)$ : only the control habitat 353 significantly differed from all other habitat types (pairwise test $p$-value $=0.026,0.015$ 354 and 0.005 when compared to the $\mathrm{AH}, \mathrm{M}$ and $\mathrm{R}$ respectively), which did not differ one 355 from one another (Table S3). Fish in the control habitat were less active overall, but the 356 difference resulted mainly from a lower number of approaches, which was responsible 357 for most of the dissimilarity between the control and other habitats (SIMPER results: 59.11, 44.18 and $47.39 \%$ for M, R and AH respectively) (Fig. 3a).

359 For D. sargus, habitat types did not significantly influence behavioral patterns. However, 360 the fishes seemed to be more active on the $\mathrm{AH}$, while almost no activity was recorded on 361 the control (Fig. 3b).

363 Habitat selection

364 For both species, all controls showed mean SI values that were not significantly different 365 from zero, indicating that, when confronted with the same habitat in the whole tank, 366 fishes did not show a preference for one side of the tank versus the other (Fig. $4 \mathrm{a} \& 4 \mathrm{~b}$ ). 367 Surprisingly, no significant deviation from zero was observed for any of the 368 combinations of habitats and for both species. However, a trend close to significance 369 was detected for D. vulgaris, which used slightly more AH than meadow (one-sample 370 Wilcoxon test $\mathrm{p}$-value $=0.058$ ).

\section{Discussion}


373 Our study revealed interspecific variations concerning the effect of habitat type on

374 survival and on the efficiency of the $\mathrm{AH}$ as a nursery rehabilitation tool. The survival of

375 D. vulgaris juveniles on the $\mathrm{AH}$ was equivalent to that observed on their natural nursery

376 habitat (rock). This species selected the AH as often as rocks while slightly dismissing

377 meadows, on which survival was the lowest. Therefore, for this species, there was

378 coherence between survival and habitat selection, which coupled with the densities

379 observed in the field (Bouchoucha et al. 2016), makes AH an efficient solution to

380 mitigate the impact of nursery habitat loss caused by the presence of harbors (Hale \&

381 Swearer 2017). The structure of the AH might then provide comparable functionality to

382 those of heterogeneous and complex natural rocky bottom (Bouchoucha et al. 2016),

383 which is corroborated by the absence of a difference in behavioral patterns between

384 both habitats. On the other hand, D. sargus juveniles experienced the lowest survival

385 rate on the $\mathrm{AH}$, and this species did not show any habitat preference. As they were not

386 preferentially choosing the $\mathrm{AH}$, the implementation of such habitats could result in the

387 formation of an "equal-preference trap" (Robertson \& Hutto 2006). These results are 388 concordant with an in situ study that found that, within Mediterranean marinas, 389 juveniles of D. vulgaris use more AH than juveniles of D. sargus (Bouchoucha et al. 2016). 390 The contrasting response observed between two close species implies that the 391 formation of eventual traps cannot be discarded. However, as natural, better quality, 392 habitat are usually not available within harbors (as this is the reason why restoration is 393 undertaken), further studies are needed to draw conclusions about the potential 394 benefits of the use of AH to rehabilitate the nursery function for juvenile coastal fishes 395 notably. These studies should include the assessment of the fitness of individuals on the 396 long term, take into account the landscape surrounding the $\mathrm{AH}$ and should also be led on 397 species naturally settling in different habitats (e.g., D. annularis individuals that settle in 
meadows and Chromis chromis individuals that settle on steep slopes of rocky reefs) or with more cryptic behavior (e.g., Epinephelus marginatus or juveniles from the Gobiidae and Blenniidae families). For cryptic juveniles, the type of $\mathrm{AH}$ used in this study might be of particular interest. Indeed, during all experimental trials, combers never entered the 402 AH. Likewise, in the field, predators have never been observed inside $\mathrm{AH}$ placed in 403 harbors, with the exception of small gobies (authors' personal observations). This 404 suggests an efficient refuge role from at least predators larger than $15 \mathrm{~cm}$. This is not the 405 case for all AH designs, as mentioned by Patranella et al. (2017), which sustains the 406 hypothesis of an adapted structure to provide protection to juveniles. Therefore, the size

407 of the cavities seems to be of prime importance to prevent the establishment of stalk 408 attack and ambush predators (Patranella et al. 2017; Almany 2004). In the wild, most 409 nursery habitats (e.g., seagrass meadows) also attract many predators. However, their 410 structural complexity provides adequate refuge for juveniles, which limits the 411 effectiveness of predators and thus limits the mortality of juveniles despite high 412 densities of predators (Anderson 2001b). The number and diversity of the cavities (i.e., 413 the complexity of a habitat) might also be a determining factor favoring multiple species 414 and size classes (Rogers et al. 2014). In that sense, an AH might be a powerful tool to 415 rehabilitate nursery function for many species if the size, number and diversity of their 416 cavities are well designed. Not only should one particular AH be designed with a variety 417 of cavities but also various AH designs should be used to mimic the heterogeneity of the 418 seascape and thus furnish complementary habitats for juveniles of different species or 419 even for different developmental stages of the same species. Indeed, in all ecosystems, 420 prey might adapt their habitat use depending on the presence of predators, which is an 421 indirect effect of predation on the prey population known as risk effect (Hamilton \& 422 Heithaus 2001). In our study, juveniles faced variable mortality rates depending on the 
423 habitat but did not have the possibility to change habitat when facing predation.

424 Additionally, if evolving in a heterogeneous seascape, they might use different habitats

425 depending on the presence and nature of the predators, which might increase their

426 survival. For instance, associating an $\mathrm{AH}$ designed to mimic a seaweed forest or

427 phanerogam meadow with one mimicking complex rocky bottom could increase

428 interhabitat connectivity and thus increase restoration efficiency (Baillie et al. 2015;

429 Traut 2005).

430 Juvenile Diplodus spp. are known to undergo ontogenic shifts in habitat use, enlarging 431 their niche by vertical (for D. vulgaris) or horizontal (for D. sargus) migration (Ventura

432 et al. 2014). Those shifts have also been observed on the AH within harbors 433 (Bouchoucha et al. 2016), and during experiments, most juveniles were observed under 434 the $\mathrm{AH}$, which seems to be the same in situ (authors' unpublished data). Changes in 435 habitat use are a widespread behavior in juvenile fish in every ecosystem (Feary et al. 436 2011; Machado et al. 2003; Schlosser 1987; Kimirei et al. 2011). Additionally, placing AH 437 at different depths and different locations could enhance its refuge role in many 438 different restoration contexts (e.g., temperate and tropical coastal waters as well as 439 lagoons and even fresh water environments, such as lakes or deep rivers).

440 One last factor that should be taken into account in $\mathrm{AH}$ conception is the material 441 employed. For example, the use of particular concrete composition and surface texture 442 is known to support enhanced fauna and flora (Perkol-Finkel \& Sella 2014). Materials 443 permitting the settlement of fouling organisms should be developed to enhance 444 potential food provision and thus increase habitat quality.

445 If $\mathrm{AH}$ might reduce the predation-induced mortality of juveniles, pollution within 446 marine urbanized areas might be greater than that in natural areas, which can increase 447 the mortality of juveniles. However, juvenile seabreams within harbors show levels of 
448 contamination and growth rates comparable to those of individuals living in adjacent 449 natural areas (Bouchoucha et al. 2018). Additionally, the risks of over-mortality linked 450 to this factor might be low. Nevertheless, restoration projects should be considered only 451 once pressures have been reduced to the lowest possible level. Indeed, if increased 452 habitat complexity might increase juvenile survival, it is important to keep in mind that 453 anthropogenic disturbances often lead to biotic homogenization (Devictor et al. 2008; 454 Olden 2006). The set of species able to live in highly urbanized areas, such as harbors, 455 might then be restricted to generalist species (Fischer \& Lindenmayer 2007). 456 Additionally, when possible, management efforts should first focus on the preservation 457 of diverse natural habitats.

458 Plasticity in fish settlement requirements might be greater than expected. Juveniles are 459 able to settle on artificial structures that can sometimes be very different from their 460 natural habitat (Guidetti 2004; Pastor et al. 2013). Even species that are only rarely 461 observed at the juvenile stage in natural habitats, such as the common dentex (Dentex 462 dentex), the black seabream (Spondyliosoma cantharus), pipefishes (Syngnathus spp.) 463 (authors' unpublished data) or even the protected dusky grouper (Epinephelus 464 marginatus) (Mercader et al. 2016), have been seen within harbors. This suggests that 465 even more specialized species could be able to live in those areas if suitable complex 466 habitats are present. Marine restoration is has more recent development than its 467 terrestrial or freshwater counterparts, and, probably due to the inherent properties of 468 marine systems (hardly accessible and highly dispersive), the range of tools available to 469 restore marine habitats remains restricted. However, projects using $\mathrm{AH}$ are increasing 470 (Seaman 2007; Brown \& Chapman 2014; Paalvast et al. 2012; Sella \& Shimrit Perkol471 Finkel 2015), and some attempts to transplant living organisms to restore marine 472 habitats are flourishing (Jaap 2000; Ng et al. 2015; Perkol-Finkel et al. 2012). 
473 Nevertheless, if the restoration of coastal fish nurseries is to be effective, efforts have to

474 be made in designing new artificial habitats and nature-based solutions, which should

475 be tested in two phases: (i) an experimental approach in aquariums to understand the

476 use by juvenile species and (ii) complex field experiments taking into account all factors

477 potentially influencing juvenile mortality and their interactions. Such studies would

478 permit confirmation and extend this work on the effect of nursery habitat restoration.

479

$480 \quad$ Acknowledgements

481 This work was financially supported by the Agence de l'eau Rhône Méditerranée Corse.

482 The funder had no role in the study design, in the collection, analysis and interpretation 483 of data, and in the decision to submit the article for publication. The authors have no 484 conflict of interests to declare. The authors would like to thank Nicolas Tapia, Laurie 485 Lebre, Gilles Saragoni, Alan Brazo, Quentin Thernon and Gaël Simon for their help in fish 486 capture and housing. They also thank Ecocean for providing the material needed to 487 build the AH and the municipal aquarium of Canet-en-Roussillon for providing seawater. 488 Finally they thank two anonymous reviewers whose comments greatly improved the 489 manuscript.

\section{References}

492 Airoldi L, Beck MW (2007) Loss, status and trends for coastal marine habitats of Europe. Oceanography and Marine Biology: an annual review 45:345-405

494 Almany GR (2004) Does increased habitat complexity reduce predation and competition in coral reef fish assemblages? Oikos 106:275-284

Anderson Marti J (2001a) Permutation tests for univariate or multivariate analysis of variance and regression. Canadian Journal of Fisheries and Aquatic Sciences 
Anderson Todd W. (2001b) Predator responses, prey refuges, and density-dependent mortality of a marine fish. Ecology 82:245-257

Andrews JE, Brawn JD, Ward MP (2015) When to use social cues: Conspecific attraction at newly created grasslands. The Condor 117:297-305

Baillie CJ, Fear JM, Fodrie FJ (2015) Ecotone effects on seagrass and saltmarsh habitat use by juvenile kekton in a temperate estuary. Estuaries and Coasts 38:1414-

Battin J (2004) When Good Animals Love Bad Habitats: Ecological Traps and the Conservation of Animal Populations: Ecological Traps. Conservation Biology $18: 1482-1491$ and Marine Nurseries for Fish and Invertebrates. BioScience 51:633

Benjamini Y, Hochberg Y (1995) Controlling the False Discovery Rate : a practical and pwerful approach to multiple testing. Journal of the Royal Statistical Society Series 57:289-300

Bouchoucha M et al. (2016) Potential use of marinas as nursery grounds by rocky fishes:

Bouchoucha M et al. (2018) Growth, condition and metal concentration in juveniles of two Diplodus species in ports. Marine Pollution Bulletin 126:31-42

Brickhill MJ, Lee SY, Connolly RM (2005) Fishes associated with artificial reefs: attributing changes to attraction or production using novel approaches. Journal of Fish Biology 67:53-71

522 Brokovich E, Baranes A, Goren M (2006) Habitat structure determines coral reef fish 
524 Brown MA, Chapman MG (2014) Mitigating against the loss of species by adding artificial intertidal pools to existing seawalls. Marine Ecology Progress Series 497:119-129

Buia MC, Gambi MC, Dappiano M (2004) Seagrass systems. Biologia Marina Mediterranea 11:133-183

529 Cardinale BJ et al. (2012) Biodiversity loss and its impact on humanity. Nature 486:5967

531 Cheminée A et al. (2016) Does habitat complexity influence fish recruitment? Mediterranean Marine Science 17:39

533 Clarke K et al. (2014) Change in marine communities: an approach to statistical analysis and interpretation. 3rd edition. PRIMER-E, Plymouth

535 Clynick BG (2008) Characteristics of an urban fish assemblage: Distribution of fish associated with coastal marinas. Marine Environmental Research 65:18-33

537 Coll J et al. (2004) Spear fishing in the Balearic Islands (west central Mediterranean): species affected and catch evolution during the period 1975-2001. Fisheries Research 70:97-111

540 Cresson P et al. (2014) Contrasting perception of fish trophic level from stomach content and stable isotope analyses: A Mediterranean artificial reef experience. Journal of Experimental Marine Biology and Ecology 452:54-62

543 Devictor V, Julliard R, Jiguet F (2008) Distribution of specialist and generalist species along spatial gradients of habitat disturbance and fragmentation. Oikos 117:507514

546 Diez D (2013) Survival analysis in R.

547 Falandysz J et al. (2002) Butyltins in sediments ans three-spined stickleback 
(Gasterosteus aculleatus) from the marinas of the Gulf of Gdańsk, Baltic sea. Journal of Environmental Science and Health, Part A 37:353-363

550 Feary DA, Burt JA, Bartholomew A (2011) Artificial marine habitats in the Arabian Gulf: Review of current use, benefits and management implications. Ocean \& Coastal Management 54:742-749

Fischer J, Lindenmayer DB (2007) Landscape modification and habitat fragmentation: a synthesis. Global ecology and biogeography 16:265-280

Foley JA (2005) Global Consequences of Land Use. Science 309:570-574

556 Guidetti P (2004) Fish assemblages associated with coastal defence structures in southwestern Italy (Mediterranean Sea). Journal of the Marine Biological Association of the United Kingdom 84:669-670

Hale R, Coleman R, et al. (2015) Identifying, preventing and mitigating ecological traps to improve the management of urban aquatic ecosystems Strecker, A, editor. Journal of Applied Ecology 52:928-939

Hale R, Swearer SE (2017) When good animals love bad restored habitats: how maladaptive habitat selection can constrain restoration Hayward, M, editor. Journal of Applied Ecology 54:1478-1486

Hale R, Treml EA, Swearer SE (2015) Evaluating the metapopulation consequences of ecological traps. Proceedings of the Royal Society B: Biological Sciences

Hamilton IM, Heithaus MR (2001) The effects of temporal variation in predation risk on anti-predator behaviour: an empirical test using marine snails. Proceedings of the Royal Society B: Biological Sciences 268:2585-2588

571 Harmelin-Vivien ML, Harmelin JG, Leboulleux V (1995) Microhabitat requirements for settlement of juvenile sparid fishes on Mediterranean rocky shores. 
574 Hewitt J et al. (2010) A latent threat to biodiversity: consequences of small-scale heterogeneity loss. Biodiversity and Conservation 19:1315-1323

Hixon MA, Jones GP (2005) Competition, predation, and density-dependent mortality in demersal marine fishes. Ecology 86:2847-2859

Houde E, Hoyt R (1987) Fish early life dynamics and recruitment variability. Am. Fish. Soc. Symp. 2:17-29

Jaap WC (2000) Coral reef restoration. Ecological Engineering 15:345-364

Jacobs J (1974) Quantitative measurement of food selection. Oecologia 14:413-417

Kaplan EL, Meier P (1958) Nonparametric Estimation from Incomplete Observations. Journal of the American Statistical Association 53:457-481

Kimirei IA et al. (2011) Ontogenetic habitat use by mangrove/seagrass-associated coral reef fishes shows flexibility in time and space. Estuarine, Coastal and Shelf Science 92:47-58

Lloret J et al. (2008) Spearfishing pressure on fish communities in rocky coastal habitats in a Mediterranean marine protected area. Fisheries Research 94:84-91

Machado LF et al. (2003) Habitat use by the juvenile dusky grouper Epinephelus marginatus and its relative abundance, in Santa Catarina, Brazil.

Macpherson E (1998) Ontogenetic shifts in habitat use and aggregation in juvenile sparid fishes. Journal of Experimental Marine Biology and Ecology 220:127-150

Martin CW et al. (2010) Differential habitat use and antipredator response of juvenile roach (Rutilus rutilus) to olfactory and visual cues from multiple predators. Oecologia 162:893-902

Martin D et al. (2005) Ecological impact of coastal defence structures on sediment and mobile fauna: Evaluating and forecasting consequences of unavoidable 
599 Meinesz A, Lefevre JR, Astier JM (1991) Impact of coastal development on the infralittoral zone along the southeastern Mediterranean shore of continental France. Marine Pollution Bulletin 23:343-347

602 Mercader $\mathrm{M}$ et al. (2016) Observation of juvenile dusky groupers (Epinephelus 603 marginatus) in artificial habitats of North-Western Mediterranean harbors.

604 Marine Biodiversity 47(2):371-372

605

606

607

Mercader M et al. (2017) Small artificial habitats to enhance the nursery function for juvenile fish in a large commercial port of the Mediterranean. Ecological Engineering 105:78-86

Mercader M et al. (2018) Spatial distribution of juvenile fish along an artificialized seascape, insights from common coastal species in the Northwestern Mediterranean Sea. Marine Environmental Research 137:60-72

Nagelkerken I et al. (2015) The seascape nursery: a novel spatial approach to identify and manage nurseries for coastal marine fauna. Fish and Fisheries 16:362-371

Neira C et al. (2011) Macrobenthic community response to copper in Shelter Island Yacht Basin, San Diego Bay, California. Marine Pollution Bulletin 62:701-717

Ng CSL et al. (2015) Enhancing the biodiversity of coastal defence structures: transplantation of nursery-reared reef biota onto intertidal seawalls. Ecological Engineering 82:480-486

Olden JD (2006) Biotic homogenization: a new research agenda for conservation biogeography. Journal of Biogeography 33:2027-2039

Paalvast P et al. (2012) Pole and pontoon hulas: An effective way of ecological engineering to increase productivity and biodiversity in the hard-substrate environment of the port of Rotterdam. Ecological Engineering 44:199-209 
623 Pastor J et al. (2013) Coastal man-made habitats: Potential nurseries for an exploited fish species, Diplodus sargus (Linnaeus, 1758). Fisheries Research 148:74-80

625 Patranella A et al. (2017) Artificial Reefs as Juvenile Fish Habitat in a Marina. Journal of Coastal Research 336:1341-1351

627

628

629

630

634

Perkol-Finkel S et al. (2012) Conservation challenges in urban seascapes: promoting the growth of threatened species on coastal infrastructures Cadotte, M, editor. Journal of Applied Ecology 49:1457-1466

Perkol-Finkel S, Sella I (2014) Ecologically active concrete for coastal and marine infrastructure: innovative matrices and designs. In: Proceeding of the 10th ICE Conference: from Sea to Shore-Meeting the Challenges of the Sea. ICE Publishing, 18-20 September 2013-Edinburgh, UK. pp. 1139-1150.

Piko AA, Szedlmayer ST (2007) Effects of habitat complexity and predator exclusion on the abundance of juvenile red snapper. Journal of Fish Biology 70:758-769

Planes S, J.-Y. Jouvenel, Lenfant P (1998) Density Dependence in Post-Recruitment Processes of Juvenile Sparids in the Littoral of the Mediterranean Sea. Oikos $83: 293-300$

R Core Team (2017) R: A language and environment for statistical computing. R Foundation for Statistical Computing, Vienna, Austria. URL http://www.Rproject.org/.

Robertson BA, Hutto RL (2006) A framework for understanding ecological traps and an evaluation of existing evidence. Ecology 87:1075-1085

Robertson BA, Rehage JS, Sih A (2013) Ecological novelty and the emergence of evolutionary traps. Trends in Ecology \& Evolution 28:552-560

Rogers A, Blanchard JL, Mumby PJ (2014) Vulnerability of coral reef fisheries to a loss of structural complexity. Current Biology 24:1000-1005 
648 Rotini A et al. (2013) Effectiveness and consistency of a suite of descriptors for assessing the ecological status of seagrass meadows (Posidonia oceanica L. Delile). 650 Estuarine, Coastal and Shelf Science 130:252-259

651 Schlosser IJ (1987) The Role of Predation in Age- and Size-Related Habitat Use by 652 Stream Fishes. Ecology 68:651-659

653

Therneau T (2015) A package for survival analysis in R.

664 Traut BH (2005) The role of coastal ecotones: a case study of the salt marsh/upland transition zone in California. Journal of Ecology 93:279-290

666 Van Dyck H (2012) Changing organisms in rapidly changing anthropogenic landscapes:

Ventura D, Jona Lasinio G, Ardizzone G (2014) Temporal partitioning of microhabitat use among four juvenile fish species of the genus Diplodus (Pisces: Perciformes, Sparidae). Marine Ecology 36:1013-1032 
673 Vigliola L, Harmelin-Vivien M (2001) Post-settlement ontogeny in three Mediterranean 674 reef fish species of the genus Diplodus. Bulletin of Marine Science 68:271-286

675 


\section{Figure captions:}

677 Figure 1: Habitat types used for survival experiments (A to D) and habitat selection 678 experiments (F to K). Artificial Habitat (A), Rock (B), Control (C), Meadow (D), Combination

679 Rock-Meadow (F), Meadow-Artificial Habitat (G), Artificial Habitat-Rock (H) and controls (I to $680 \mathrm{~K})$.

681 Figure 2: Kaplan-Meier survival curves for each habitat with 95\% confidence intervals. 682 Lowercase letters indicate the results of pairwise tests; habitats sharing at least one letter do 683 not differ. (A) D. vulgaris and (B) D. sargus.

684 Figure 3: Mean number (error bar + SD) of behavioral observations for the comber 685 (approach and attack) and the juveniles (escape) for the first 30 min of the predation 686 experiments on (A) D. vulgaris, (B) D. sargus. Lowercase letters indicate the results of 687 pairwise tests; habitats sharing at least one letter do not differ.

688 Figure 4: Boxplots of the spread of Jacob's Selection index for (A) D. vulgaris, (B) D. sargus. 689 Vertical black lines indicate the median; the ends of the boxes, the first and third quartiles; 690 the whiskers, the values whose distance from the box is at most 1.5 times the interquartile 691 range; the points, extreme values and black crosses, the mean values. 
Figures:

694 Figure 1:
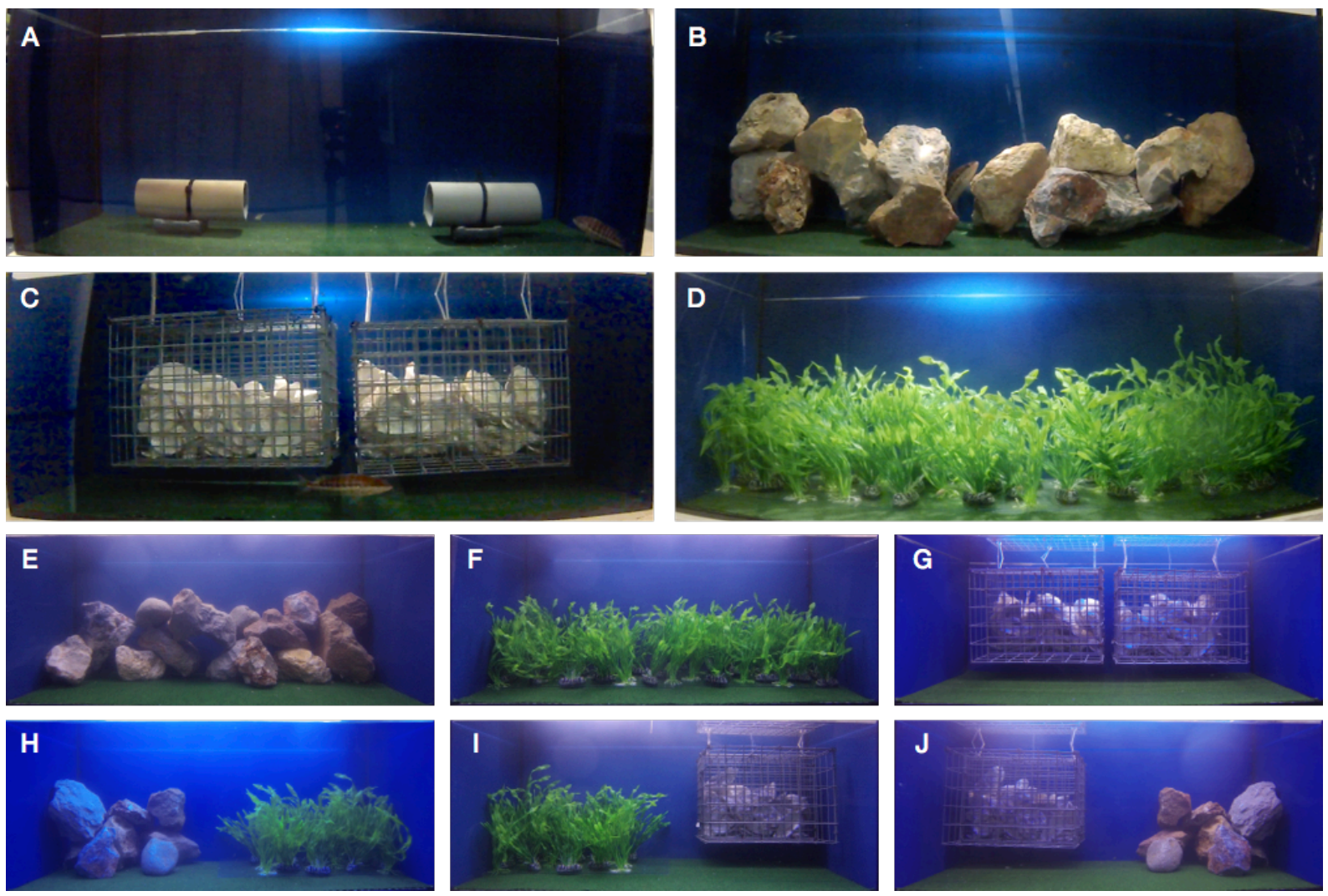

696

697

698

699

700

701

702 
Figure 2:
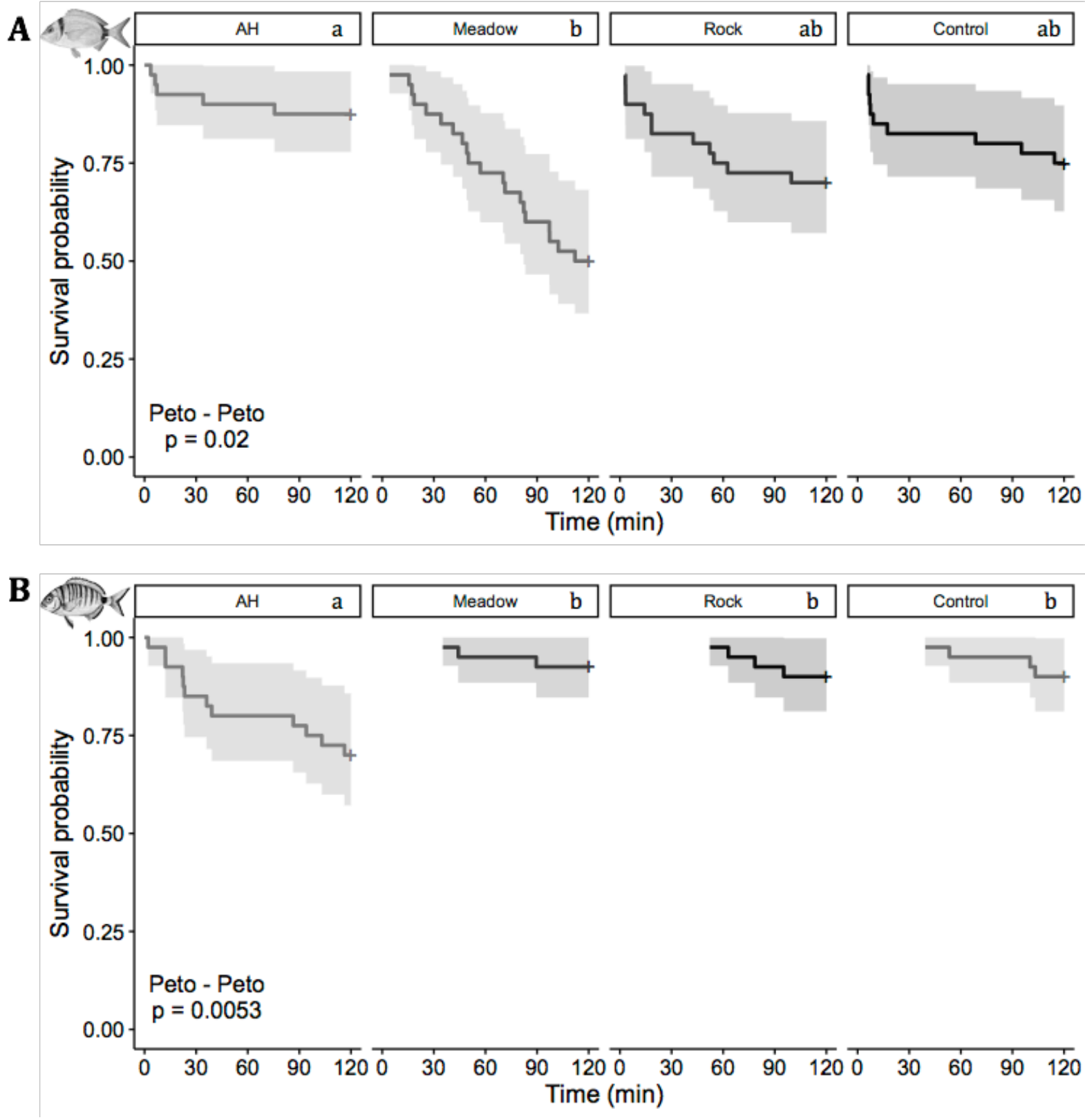

705

706

707

708 
709 Figure 3:
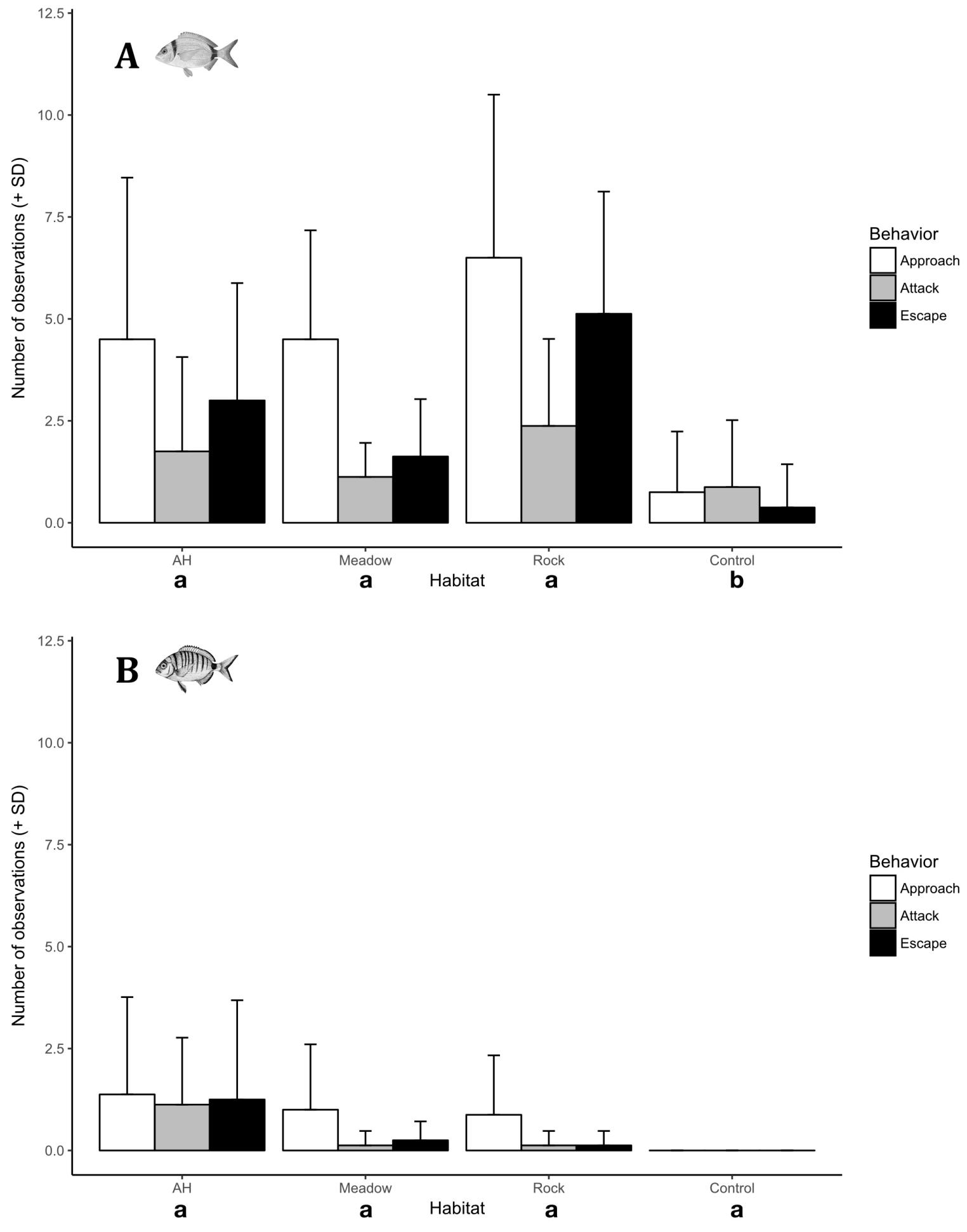
713 Figure 4:
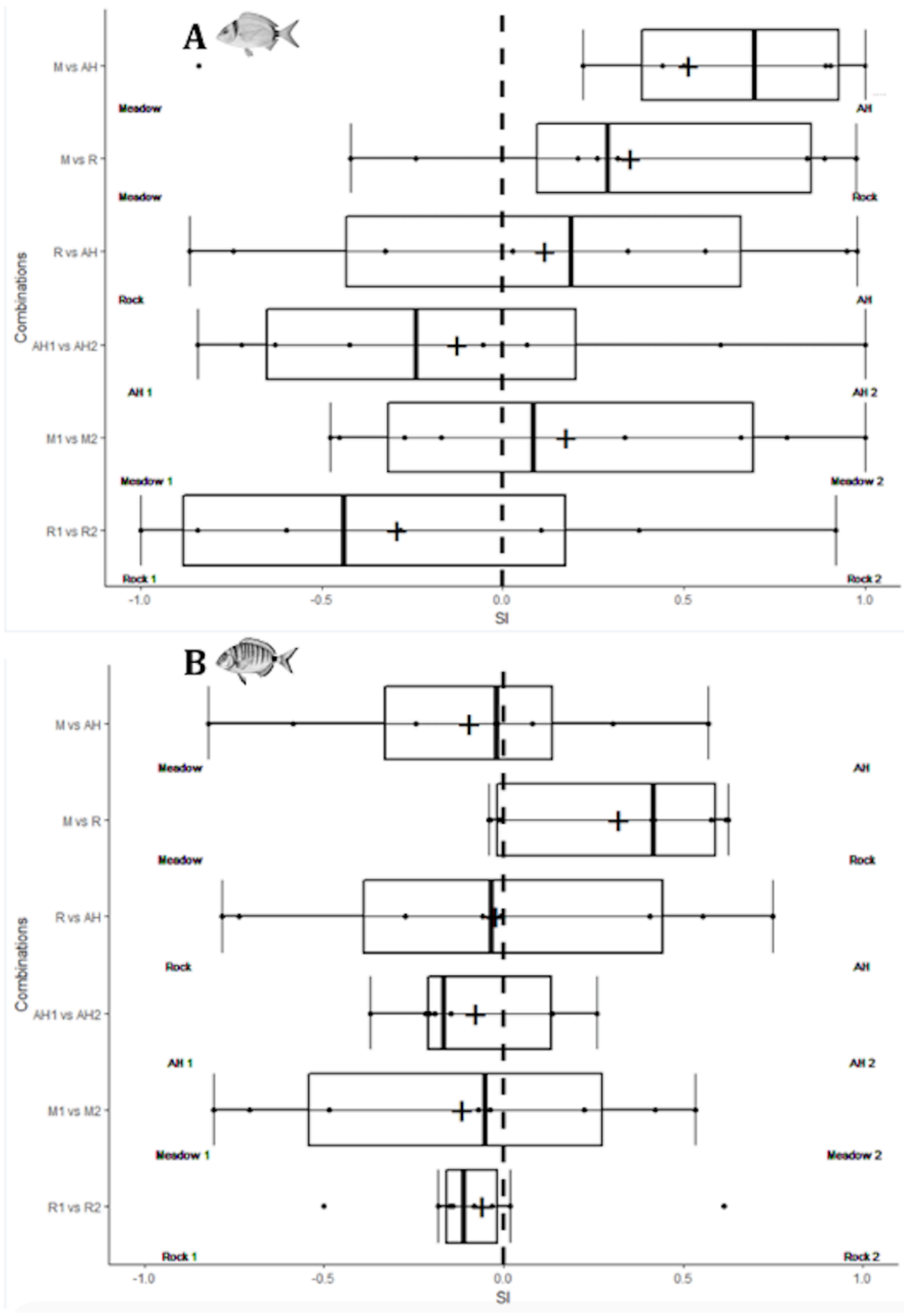